\title{
Introduction to special issue: papers from UML\&FM
}

\author{
Jean-Michel Bruel • Agusti Canals • \\ Sébastien Gérard · Isabelle Perseil
}

Published online: 10 December 2008

(C) Springer-Verlag London Limited 2008

Erratum to: Innovations Syst Softw Eng (2008)

4:185-187

DOI 10.1007/s11334-008-0061-4

Unfortunately, an error occurred in paragraph 5 in this article. Stefan Gruner was a member of the panel instead of Sébastian Gerard. The corrected paragraph is given below.

\section{Panel}

A set of questions and answers have served as a conclusive discussion through a panel animated by the organizers. The panelists were Jean Bézivin, Jean-Michel Bruel, Stefan Gruner and Frédéric Mallet. A summary of the discussions is available on the workshop web site mentioned earlier.

The online version of the original article can be found under doi:10.1007/s11334-008-0061-4.

J.-M. Bruel (凶)

IRIT, Université Toulouse, 31700 Blagnac, France

e-mail: bruel@iut-blagnac.fr

A. Canals

C-S, 31500 Toulouse, France

e-mail: agusti.canals@c-s.fr

S. Gérard

CEA, 91191 Gif-sur-Yvette, France

e-mail: gerard@cea.fr

I. Perseil

TELECOM ParisTech, 75013 Paris, France

e-mail: isabelle.perseil@telecom-paristech.fr 